\title{
Processamento Anafórico e Leitura: revisão sistemática e ponderações para ensinar e aprender a ler
}

\author{
Bruna Alexandra FRANZEN* \\ Ana Cláudia de SOUZA**
}

\begin{abstract}
* Doutoranda em Linguística pela Universidade Federal de Santa Catarina (UFSC). Mestra (2012) em Educação pela Universidade Regional de Blumenau (FURB). Contato: brunalexandra.f@gmail.com.

* Doutora (2004) em Linguística pela Universidade Federal de Santa Catarina (UFSC). Pós-Doutorado (2006) pela UFSC. Professora do Departamento de Metodologia de Ensino e do Programa de Pós-Graduação em Linguística da UFSC. Contato: ana.claudia.souza@ufsc.br.
\end{abstract}

\section{Resumo:}

Este artigo investiga a relação entre processamento anafórico e leitura em perspectiva psicolinguística, visando conhecer e analisar estudos brasileiros que relacionam esses dois eixos e propor ponderações sobre implicações pedagógicas ao ensino da leitura. Trata-se, pois, de pesquisa bibliográfica, desenvolvida pelo método de revisão sistemática e pelo estudo da literatura acerca do processamento e da compreensão em leitura e do seu ensino. As pesquisas analisadas no estudo de revisão são experimentais e seus resultados demonstram diferenças de custos de processamento geradas por distintas construções anafóricas. Quanto às implicações pedagógicas, as ponderações respaldam-se nos seguintes princípios: i) leitura se ensina; ii) o estímulo a que o/a leitor/a acessa visando à compreensão é o texto escrito; iii) a natureza e a constituição do texto têm implicações diretas tanto no processamento quanto no seu resultado; iv) o texto escrito se constitui por meio de uma trama da qual a correferenciação é parte importante; v) a resolução de anáforas, portanto, é fundamental à compreensão dos textos e deve ser explícita e sistematicamente ensinada, não se tratando, assim, de análise do texto pelo texto em sala de aula, mas de sua análise na relação com o/ a leitor/a em atividade de leitura objetivando a compreensão.

\section{Palavras-chave:}

Processamento anafórico. Ensino e aprendizagem de leitura. Revisão sistemática.

Signum: Estudos da Linguagem, Londrina, v. 23, n. 1, p. 9-30, abr. 2020 


\section{Processamento Anafórico e Leitura: revisão sistemática e ponderações para ensinar e aprender a ler}

Bruna Alexandra Franzen; Ana Cláudia de Souza

\section{INTRODUÇÃo}

Desde que os objetivos de ensino se guiam pela intenção de promover aprendizagem significativa, relevante, interessante, inclusiva e democrática, o ensino da leitura e, como parte inerente dele, da compreensão, tornou-se foco de atenção daqueles que elaboram as políticas públicas, de pesquisadores/as, de gestores/as educacionais e de professores/as que atuam na relação direta com os/as estudantes visando incrementar processos de ensino que conduzam ao aprender a ler. Abunda literatura consistente produzida por estudiosos/as que se dedicam a investigar não apenas a leitura, ela mesma na relação que o/a leitor/a estabelece com o texto com vistas a alguma sorte de compreensão, como também aspectos relativos especificamente ao/à leitor/a - tais como processos afetivos, perceptivos, atencionais e de memória -, ao texto - a exemplo de sua constituição linguística interna, forma, função e gênero -, ao contexto e à situação - ou seja, como fatores sociais, econômicos e culturais participam deste processo - e, ainda - o que é fundamental a este estudo -, como esse conjunto de fatores opera e pode ser explorado no processo de ensinar a ler (vide pesquisas publicadas em obras, como: Flood, 1984; Ruddell; Ruddell; Singer, 1994; Oakhill; Cain; Elbro, 2017; Kamil et al., 2011; ${ }^{1}$ Alvermann; Unrau; Ruddell, 2013; Snowling; Hulme, 2013; entre muitas outras).

Neste trabalho, no qual estarão em destaque as relações anafóricas, voltaremos nosso olhar a um dos aspectos relativos ao texto na sua relação com o/a leitor/a: a correferenciação, uma vez que as anáforas são parte do texto e, assim, participam também da produção de sentidos do escrito, realizada pelo/a leitor/a, em atividades de leitura. Afinal, um texto não diz respeito a uma sequência de palavras e frases em que basta, ao/à leitor/a, compreender cada uma delas isoladamente. Tampouco é suficiente que se compreendam as relações locais intra ou interfrasais. Todavia, sem a compreensão local, não há possibilidade de integração, elaboração e produção de representação mental do escrito que seja consistente e coerente com o texto. É necessário que os elementos textuais estejam relacionados entre si, que existam conexões de modo a garantir a manutenção tópica e temática, que haja sequência e organização em torno do que é dito e que o/a leitor/a perceba e compreenda as relações e o conteúdo do texto. Mas não apenas isso. No que diz respeito ao que interessa particularmente a este estudo, o texto deve, ainda, ter uma progressão no que tange à temática estabelecida. Esse fator, junto ao encadeamento, leva a diversas formas de retomar aquilo sobre o que se está discorrendo, a fim de constituir a trama textual, que precisa estar adequadamente tecida para que, então, os processos de compreensão em leitura do escrito sejam adequadamente implementados em uma relação, que, espera-se, resulte bem-sucedida, do/a leitor/a com o texto em uma situação específica.

\footnotetext{
${ }^{1}$ Esta obra, organizada por Kamil, Pearson, Moje e Afflerbach e publicada em formato eletrônico em 2011, é um handbook, parte de um conjunto de obras que vem sendo publicado desde o ano 1984, apresentando atualizações no campo da pesquisa em leitura no período relativo à cobertura de cada volume. O quinto volume deste handbook estará disponível ainda em 2020. É possível acessar informações sobre seu conteúdo em: https://bit.ly/34QavxY. Acesso em: 16 abr. 2020.
} 
As discussões em torno do processamento anafórico são caras à Psicolinguística e, neste contexto, pesquisas vêm sendo desenvolvidas ao longo dos anos, a fim de conhecer o processamento da anáfora, relacionando diferentes variáveis e teorias, por meio de diferentes métodos e tarefas. Com isso em mente e por conta da relevância desse aspecto microtextual à construção da coerência de um texto em leitura, o presente artigo busca, por meio de um mapeamento dos estudos brasileiros a respeito do processamento da anáfora em estímulos escritos, realizado sob o método de revisão sistemática, conhecer e analisar tais estudos, para, então, propor ponderações sobre implicações pedagógicas, considerando os seus resultados à luz da literatura, na qual se embasam a Psicolinguística e a Psicolinguística Aplicada, acerca do processamento, da compreensão e da aprendizagem - e ensino - da leitura.

A partir disso, é possível tecer uma descrição sobre o funcionamento do processamento anafórico durante a compreensão leitora e contribuir para a pesquisa sobre o ensino da leitura, considerando seu processamento. Este estudo se guia pelos seguintes questionamentos: como tem sido investigada, no Brasil e sobre o Português Brasileiro (PB), a relação entre processamento anafórico e leitura na área da Psicolinguística? Como esses estudos podem contribuir para o ensino da leitura de textos? Diante de tais questões, os termos-chave desta pesquisa são 'processamento anafórico' e 'leitura' e, por tratar-se de processamento da linguagem, a área de inserção é a Psicolinguística. Vale destacar, entretanto, que não necessariamente os estudos analisados inscreveram-se, explicitamente, nesta área e assumiram que estavam investigando processos de leitura. Foi suficiente que tenham investigado processamento, que os estímulos dos testes aplicados para a coleta de dados tenham sido escritos e significativos e que a anáfora correferencial tenha sido o elemento-alvo da investigação para a inclusão do estudo na revisão sistemática, que tratou somente de pesquisas que lidaram com dados primários.

Dentre os temas recorrentes na Psicolinguística estão os processos envolvidos na compreensão da linguagem - e, em especial para os nossos interesses investigativos, na compreensão do texto escrito - dos quais o processamento anafórico participa (GAGNÉ; YEKOVICH; YEKOVICH, 1993; KINTSCH, 1998; KINTSCH; RAWSON, 2013; OAKHILL; CAIN; ELBRO, 2017). A compreensão se dá a partir de diferentes fatores contidos em um texto, como os elementos de coesão, que possibilitam ao/à ouvinte ${ }^{2}$ ou ao/à leitor/a fazer as inferências necessárias e, assim, constituir a coerência e formular as suas compreensões. Para uma compreensão adequada, suficiente e que promova a produção de sentidos, é fundamental o envolvimento de diversos aspectos, entre eles, as formas de retomada. No fluir do texto, um elemento sobre o qual se está tratando é citado de diferentes maneiras, formando relação correferencial que participa da produção de sentido. Assim, de acordo com Teixeira (2013), a anáfora correferencial tem o papel de retomar um elemento já mencionado. A retomada pode ocorrer de diferentes formas, por meio de um pronome, de um demonstrativo, de um nulo ou de um sintagma nominal. Fato é que, para que haja a correferencialidade, anáfora e antecedente devem dizer respeito ao mesmo referente.

Existem construções anafóricas que podem requerer do/a leitor $/ \mathrm{a}^{3}$ conhecimentos prévios ou inferências a serem feitas a partir da informação dada. Este artigo se volta àquelas que possuem um referente específico, determinado no próprio texto (diferente de anáforas associativas, ${ }^{4}$ por exemplo). Está-se pensando,

\footnotetext{
${ }^{2}$ Esta pesquisa trata de língua cuja materialidade primária é oral: o português brasileiro. Todavia, destaca-se que os aspectos coesivos são relevantes também ao acesso e à compreensão de línguas não orais, a exemplo das línguas de sinais.

${ }^{3}$ Embora a anáfora seja elemento constitutivo de quaisquer textos, aqui o foco está apenas nos escritos, em razão do recorte deste estudo.

${ }^{4}$ Como em: "A casa era a mais bela da cidade, a porta de entrada trazia a sofisticação da antiguidade". Nesse caso, automaticamente é percebido que porta diz respeito à porta da casa. Para tanto, é necessário que o/a leitor/a saiba que uma casa possui porta, pois essa informação não está explícita no texto. A correferencialidade se dá, assim, por meio do conhecimento prévio, constituindo o que se denomina de anáfora associativa (KOCH; ELIAS, 2015).
} 
portanto, sobre as relações estabelecidas internamente no texto, especialmente nas implicações delas para os processos bottom-up, ou seja, para os processos nos quais o texto é o ponto de partida na direção do acionamento de conhecimentos prévios do/a leitor/a, tendo-se estabelecido as relações intratextuais. Kintsch e Rawson (2013, p. 233) definem a anáfora dando destaque ao fato de ela se referir particularmente a um conceito anteriormente mencionado. Nesse sentido, "qualquer dispositivo linguístico que possa ser usado para se referir a um conceito já mencionado se chama anáfora, e a resolução anafórica é o processo psicológico de identificar o conceito (ou referente) mencionado antes, ao qual se refere à anáfora”. É sobre esse tipo de anáfora, abrigado pelo conceito expresso por Kintsh e Rawson, que este estudo se debruça, ou seja, a anáfora correferencial ou direta.

Diante disso - e tendo em vista que o processo de leitura proficiente é inerentemente estratégico e, por isso (entre outras razões), cognitivamente complexo e dispendioso -, é necessário que o processamento de nível local, onde residem as relações correferenciais que participam da trama textual, ocorra de modo automático, de sorte que o/a leitor/a busque, com rapidez e eficiência, pelas relações internas contidas em um texto (KINTSCH, 1998). As relações correferenciais atuam, portanto, na formação da base textual, ou seja, na microestrutura, e refletem na compreensão global do texto. Além disso, de acordo com Teixeira (2013, p. 24), a investigação da resolução da anáfora tenta "responder aos problemas ligados à nossa capacidade de reter a informação recentemente lida em nossa memória e à nossa capacidade de integrar esta informação às demais que vão sendo ativadas durante a leitura de um texto”. Assim, as anáforas fazem parte do tecido textual, ou seja, são responsáveis pelas conexões e dão continuidade a uma ideia, de modo a oferecer progressão em torno do que é dito. Entendendo as representações mentais que ocorrem ao se processarem essas estruturas, caminha-se na direção de compreender a forma como o cérebro processa a arquitetura textual, que é tecida por diversas microestruturas que abrangem aspectos fonológicos, morfológicos, lexicais, sintáticos e semânticos.

Ao olhar para o processamento anafórico, busca-se pelo entendimento de como a progressão textual atua nos aspectos cognitivos da compreensão e como os diversos sistemas da cognição estão envolvidos no processamento desse aspecto específico, a fim de propor implicações pedagógicas ao ensino da leitura. Conforme menciona Leitão (2005), a memória de trabalho está diretamente envolvida no processamento anafórico, pois, a depender da forma como a anáfora é construída, os custos podem ser maiores ou menores para esse sistema. Quanto maior a demanda para a memória de trabalho, mais esforço será requerido para a manutenção da informação, de modo que ela possa ser devidamente processada e vinculada tanto ao dado quanto ao novo, e mais estratégico deverá ser o/a leitor/a para desempenhar adequadamente a tarefa aumentando as chances de alcance dos seus objetivos (SOUZA, 2004). Tal tarefa pode ser bastante dispendiosa e resultar em diminuição do desempenho e aumento do tempo de execução da tarefa se o/a leitor/a não for suficientemente hábil em leitura. Essa é uma das razões pelas quais as relações anafóricas devem ser ensinadas quando se tem por propósito ensinar a ler, de sorte a favorecer um processamento eficiente e eficaz que possibilite a compreensão (KINTSCH; RAWSON, 2013; KOCH; ELIAS, 2015; OAKHILL; CAIN; ELBRO, 2017; SOUZA; SEIMETZ-RODRIGUES; WEIRICH, 2019).

\section{MÉTODO}

Quanto ao método empregado, esta é uma pesquisa bibliográfica (GIL, 2017; MARCONI; LAKATOS, 2017; SEVERINO, 2017), desenvolvida em dois momentos, segundo seus objetivos. Na primeira fase, realizou-se uma revisão sistemática (NOiBREGA-THERRIEN; THERRIEN, 2004; SAMPAIO; MANCINI, 2007; HIGGINS; GREEN, 2008; DE-LA-TORRE-UGARTE-GUANILO; TAKAHASHI, BERTOLOZZI, 2011; RAMOS; FARIA; FARIA, 2014) - que possibilita o mapeamento dos estudos acerca de um determinado objeto de conhecimento -, com o propósito de conhecer e analisar as pesquisas brasileiras que se dedicaram à 
investigação do processamento da anáfora em estímulos escritos, em atividade de leitura. Na segunda fase, de posse da análise dos estudos e da literatura que embasa a ciência da leitura - seu processamento, compreensão, aprendizagem e ensino - e o processamento da anáfora, discutiram-se e apresentaram-se implicações pedagógicas para o ensino da leitura.

Conforme esclarece Gil (2017), a principal vantagem da pesquisa bibliográfica é que ela possibilita que o pesquisador cubra uma ampla gama de fenômenos, maior do que a que poderia investigar diretamente e por meio do levantamento de dados primários. Tal fator é positivo para a pesquisa que ora se apresenta, uma vez que, quanto mais se conhecer a respeito do que vem sendo investigado, mais se poderá tratar das implicações pedagógicas do método e do resultado desses estudos para o ensino da leitura, competência que não se tem atingido suficientemente na educação básica brasileira (MORAIS, 2014; KENEDY, 2018; SCLIAR-CABRAL, 2018).

Sendo um tipo de pesquisa bibliográfica, a revisão sistemática, a seu turno, é um método de pesquisa que requer rigor, clareza e critérios suficientemente definidos, de sorte que seja possível reconduzir a investigação, utilizando os mesmos parâmetros. Ela é caracterizada por dispor de objetivos com critérios pré-definidos de elegibilidade de estudos a serem selecionados, de metodologia explícita e detalhada, de busca sistemática, a fim de identificar todos os estudos que podem se enquadrar nos critérios de elegibilidade, de apresentação e síntese, também sistemáticas, das características e dos resultados dos estudos incluídos (HIGGINS; GREEN, 2008). "Nessa perspectiva, os estudos que têm por finalidade a realização [deste tipo de] revisão permitem a compreensão do movimento da área, sua configuração, propensões teóricas metodológicas, análise crítica indicando tendências, recorrências e lacunas" (RAMOS-VOSGERAU; ROMANOWSKI, 2014, p. 167).

Conforme esclarece o documento Diretrizes Metodológicas: elaboração de revisão sistemática e metanálise de ensaios clínicos randomizados (BRASIL, 2012), sendo um método de síntese de evidências confiável, auditável e rigoroso, a revisão sistemática permite interpretar e, criticamente, avaliar todas as pesquisas disponíveis e relevantes que foram cobertas pelos critérios e meios de busca e seleção, definidos conforme os objetivos, de sorte a poder tratar, profunda e consistentemente, de uma questão particular, de um problema ou de um fenômeno de interesse investigativo. Considerando o exposto, registra-se que, embora a revisão sistemática seja um método de pesquisa muito frequentemente empregado em outras áreas, a exemplo da saúde, das engenharias e das ciências sociais aplicadas, trata-se de método de grande valia para todas as áreas de conhecimento, que permite não apenas conhecer o próprio campo de pesquisa, como explorá-lo e mais claramente desenvolvê-lo, de sorte a buscar ganhos em pesquisa básica e aplicada. O estudo de Ramos, Faria e Faria (2014), por exemplo, trata da revisão sistemática como um método de pesquisa na área das Ciências da Educação, suscitando questões de grande relevância ao avanço das pesquisas.

O levantamento dos estudos para a revisão que ora apresentamos foi realizado em janeiro de 2020, a partir dos seguintes descritores: "processamento anafórico" (utilizado entre aspas), processamento anafórico AND psicolinguística (sem aspas e com uso do operador booleano AND) e "processamento anafórico" AND "leitura" (ambos os descritores entre aspas e com o operador booleano AND). O recorte temporal dos estudos selecionados incluiu aqueles publicados até o momento da busca, tendo sido encontrados trabalhos somente até o ano de 2017. Não há, portanto, nas bases de dados pesquisadas, estudos que tenham sido publicados em 2018, 2019 e 2020. O levantamento foi realizado em bases que disponibilizam textos completos e congregam teses, dissertações e artigos. A busca ocorreu na Biblioteca Digital Brasileira de Teses e Dissertações (BDTD), no Pro Quest Dissertations and Theses, no Directory of Open Access Journal e no Portal de Periódicos Capes. ${ }^{5}$

\footnotetext{
${ }^{5}$ Vale ressaltar que o ponto de partida para a seleção das bases foi o banco disponibilizado pela Universidade Federal de Santa Catarina, constante da página: http:// bit.ly/3aQvN2j.
} 
A fim de responder aos critérios de elegibilidade, os estudos, necessariamente, tinham de: i) desenvolver-se quanto aos seus objetivos mais gerais, em perspectiva exploratória, descritiva ou explicativa; ii) seus métodos tinham de implicar coleta e análise de dados primários, seja por meio de pesquisa experimental, estudo de coorte, estudo de caso, pesquisa-ação ou interveniente; iii) situar-se na área multidisciplinar Psicolinguística; iv) eleger como objeto de investigação o processamento anafórico de estímulos escritos do $\mathrm{PB}$, o que implica necessariamente processos de leitura. Foram excluídos os estudos que não responderam a quaisquer dos critérios de elegibilidade.

Como resultado da busca e seleção, restaram apenas 14 trabalhos. Nenhum trabalho repetido foi incluído. Nos casos de pesquisas de conclusão de mestrado e doutorado - dissertações e teses - cujo texto ou parte dele tenha sido transformado em artigo de periódico, a publicação derivada foi considerada apenas quando o trabalho principal não foi localizado nas bases de dados. Nos demais casos, houve apenas menção à localização de publicações correspondentes aos mesmos dados e resultados. Esse procedimento visou tão somente à garantia de mais adequada cobertura das investigações-alvo desta pesquisa, e não implicou aumento do número de pesquisas analisadas.

No que diz respeito aos descritores, é importante destacar que foram realizadas buscas com termos mais restritivos - processamento anafórico AND leitura e processamento anafórico AND psicolinguística - e também com termo que poderia abarcar um número maior de estudos, por ser mais amplo e não exigir explicitamente a relação que neste estudo estamos estabelecendo - processamento anafórico. Mesmo assim, ao se aplicarem os critérios de inclusão e exclusão, o número de estudos não aumentou.

Quanto às implicações pedagógicas, as reflexões propositivas desenhadas se baseiam tanto na revisão sistemática realizada quanto na literatura teórica sobre os processos de leitura - envolvendo processamento, compreensão, aprendizagem e ensino - e acerca do processamento anafórico. As/Os seguintes principais obras e textos embasam a proposta: Ruddell, Ruddell e Singer (1994); Alvermann; Unrau; Ruddell (2013); Snowling e Hulme (2013); Oakhill, Cain e Elbro (2017); e Souza; Seimetz-Rodrigues; Weirich (2019).

\section{As Pesquisas que Investigam o Processamento Anafórico de Estímulo Verbal ESCRITO: REVISÃo SISTEMÁTICA}

Os/As participantes dos estudos analisados são, majoritariamente, adultos/as universitários/as, sem qualquer atipicidade, com exceção do trabalho de Correia (2014), que investigou pessoas que gaguejam. Todas as pesquisas partem de uma abordagem experimental, ou seja, tendo definido o objeto de estudo (o processamento anafórico), elas selecionam as variáveis que podem influenciar em seu processamento. Além disso, são definidas formas de controle e, então, são observados os efeitos que a variável produz no objeto (GIL, 2017). No entanto, possuem diferentes variáveis e distintas formas de controle e testagem.

No Quadro 1, a seguir, são apresentados todos os trabalhos catalogados, discorrendo-se, em seguida, sobre onde foram desenvolvidos. Dos dados selecionados para compor o quadro, consta orientador/a, quando se trata de pesquisa de pós-graduação, já que a realização de tais estudos não ocorre senão por meio de coautoria. Quando se trata de artigo derivado de pesquisas desenvolvidas sob orientação não disponibilizadas nas bases de dados pesquisadas, os artigos delas decorrentes indicam, em sua maioria, o orientador como coautor do texto; por isso, os nomes constam da coluna "autor/a". São exemplos disso: Márcio Martins Leitão e Antônia Barros Gibson Simões (2011) e Gitanna Brito Bezerra e Márcio Martins Leitão (2013). Apenas no artigo de Leitão (2010), cujos dados são provenientes de sua tese de doutorado (2005), desenvolvida sob orientação de Maia (UFRJ), não há indicação do orientador como coautor. 
Quadro 1 - Trabalhos que estudam o processamento anafórico

\begin{tabular}{|c|c|c|c|c|c|c|}
\hline & Tipo $^{6}$ & Autor(es)/a(s) & Orientador/a & Data & Local & Técnicas \\
\hline 1 & $\mathrm{~T}$ & Maria Luiza Cunha-Lima & $\begin{array}{l}\text { Ingedore Grunfeld Villaça } \\
\text { Koch }\end{array}$ & 2004 & UNICAMP & $\begin{array}{l}\text { Leitura automonitorada e Teste } \\
\text { de aceitabilidade de sentenças }\end{array}$ \\
\hline 2 & $\mathrm{D}$ & Karla Lima de Queiroz & Márcio Martins Leitão & 2009 & UFPB & Leitura automonitorada \\
\hline 3 & $\mathrm{~A}$ & Márcio Martins Leitão & - & 2010 & - & Leitura automonitorada \\
\hline 4 & A & $\begin{array}{l}\text { Márcio Martins Leitão; } \\
\text { Antônia Barros Gibson } \\
\text { Simões }\end{array}$ & - & 2011 & - & Leitura automonitorada \\
\hline 5 & $\mathrm{~T}$ & $\begin{array}{c}\text { Elisângela Nogueira } \\
\text { Teixeira }^{7}\end{array}$ & Maria Elias Soares & 2013 & UFC & Rastreamento ocular \\
\hline 6 & A & $\begin{array}{l}\text { Gitanna Brito Bezerra; } \\
\text { Márcio Martins Leitão }\end{array}$ & - & 2013 & - & Leitura automonitorada \\
\hline 7 & $\mathrm{D}$ & $\begin{array}{c}\text { Jefferson de Carvalho } \\
\text { Maia }\end{array}$ & Maria Luiza Cunha Lima & 2013 & UFMG & $\begin{array}{l}\text { Leitura automonitorada, Teste de } \\
\text { julgamento de aceitabilidade e } \\
\text { rastreamento ocular }\end{array}$ \\
\hline 8 & $\mathrm{D}$ & $\begin{array}{c}\text { Ludmila Pimenta Salles } \\
\text { Milhorance }\end{array}$ & $\begin{array}{c}\text { Cilene Aparecida Nunes } \\
\text { Rodrigues }\end{array}$ & 2014 & PUC-RIO & $\begin{array}{l}\text { Teste de julgamento de } \\
\text { gramaticalidade/aceitabilidade de } \\
\text { sentenças }\end{array}$ \\
\hline 9 & $\mathrm{D}$ & $\begin{array}{l}\text { Antônia Barros Gibson } \\
\text { Simões }\end{array}$ & Márcio Martins Leitão & 2014 & UFPB & Leitura automonitorada \\
\hline 10 & $\mathrm{D}$ & $\begin{array}{c}\text { Débora Vasconcelos } \\
\text { Correia } 9\end{array}$ & José Ferrari Neto & 2014 & UFPB & $\begin{array}{l}\text { Leitura automonitorada e Teste } \\
\text { de tempo de reação serial } \\
\text { alternada }\end{array}$ \\
\hline 11 & $\mathrm{D}$ & Judithe Jenuíno Henrique & Rosana Costa de Oliveira & 2016 & UFPB & $\begin{array}{l}\text { Teste de julgamento de } \\
\text { aceitabilidade }\end{array}$ \\
\hline 12 & $\mathrm{D}$ & $\begin{array}{c}\text { Elioenai Macena de } \\
\text { Araújo }\end{array}$ & Rosana Costa de Oliveira & 2017 & UFPB & Leitura automonitorada \\
\hline 13 & $\mathrm{~T}$ & $\begin{array}{c}\text { Liliane Carvalho Félix } \\
\text { Cavalcante }\end{array}$ & $\begin{array}{c}\text { Jan Edson Rodrigues } \\
\text { Leite }\end{array}$ & 2017 & UFPB & $\begin{array}{l}\text { Teste cloze e testes de } \\
\text { compreensão em leitura }\end{array}$ \\
\hline 14 & $\mathrm{D}$ & $\begin{array}{c}\text { Eva Vilma Aires Cabral } \\
\text { Gondim }\end{array}$ & Márcio Martins Leitão & 2017 & UFPB & Teste de leitura automonitorada \\
\hline
\end{tabular}

Fonte: Elaborado pelas autoras.

Para que se conheçam os centros de desenvolvimento das pesquisas, vale destacar o local e a instituição onde vêm sendo desenvolvidas. Dos estudos que resultaram em trabalhos de tese ou dissertação, sete foram realizados na Universidade Federal da Paraíba (UFPB), três deles orientados por Márcio Martins Leitão. Os artigos que retornaram com as buscas dizem respeito a estudos produzidos por pesquisadores/as da UFPB: um deles de Leitão e outros dois orientados por ele. Os outros quatro estudos foram realizados em diferentes universidades, quais sejam: Universidade Federal de Minas Gerais (UFMG), Universidade Estadual de Campinas (Unicamp), Universidade Federal do Ceará (UFC) e Pontifícia Universidade Católica do Rio de Janeiro (PUC-RIO). Cabe a observação de que a maioria dos estudos é fruto de pesquisas conduzidas em instituições públicas de ensino superior, o que revela a importância dessas instituições no desenvolvimento das pesquisas no Brasil.

6 "T" = tese; "D" = dissertação; e "A" = artigo.

7 A publicação de Teixeira, Fonseca e Soares (2014), localizada nas buscas, não foi incluída porque dados e resultados provêm da tese de Teixeira (2013).

${ }^{8}$ O artigo de Bezerra e Leitão (2013), incluído nesta revisão sistemática, apresenta dados e resultados da dissertação de Bezerra (2013), desenvolvida sob orientação de Leitão. A dissertação não foi incluída porque não retornou nas buscas realizadas nesta revisão sistemática.

9 O artigo de Correia, Ferrari-Neto e Leitão (2013), localizado nas buscas, não foi incluído porque discute dados constantes da dissertação de Correia (2014). 


\section{As Técnicas Utilizadas}

Há três técnicas que são comuns e que aparecem (ao menos uma delas) em quase todas as pesquisas ou em, pelo menos, duas delas, a saber: leitura automonitorada, teste de julgamento de aceitabilidade e rastreamento ocular. ${ }^{10}$ São, portanto, as técnicas mais utilizadas quando se trata de estudar o processamento anafórico.

A leitura automonitorada e o rastreamento ocular são técnicas comportamentais que se baseiam no tempo de resposta e buscam por resultados que captam o processamento em curso, ou seja, são considerados métodos on-line (KAISER, 2013). Normalmente, ambas as técnicas vêm conjugadas a perguntas de compreensão, para checar a atenção e a compreensão do participante. O teste de leitura automonitorada busca "medir quanto tempo as pessoas gastam para ler palavras ou frases" (KAISER, 2013, p. 139-140, tradução nossa). O estímulo experimental pode estar segmentado em palavras, sintagmas ou pode ser apresentada a frase inteira. De toda forma, a intenção é obter o tempo que o/a participante leva para fazer a leitura, e o resultado aferido é relacionado ao custo de processamento. Quanto mais tempo gasto, maior o custo para o processamento. Isso traz evidências sobre os processos cognitivos que ocorrem diante de um determinado fenômeno (SOUZA; FRANZEN; SCHILICHTING, 2019).

O rastreamento ocular, por sua vez, é uma técnica comportamental on-line que capta, diretamente, os movimentos oculares realizados pelo participante durante a leitura (MAIA, 2018). Com o uso desse paradigma, é possível o trabalho com textos maiores, o que pode gerar resultados mais próximos de uma experiência de leitura natural, salvo pelo fato de à face/cabeça do participante ser acoplado o dispositivo que permite medir e registrar os movimentos oculares. Durante a leitura, os olhos realizam movimentos sacádicos, com pontos de paradas, ou seja, os olhos não se fixam em cada uma das palavras isoladamente. Dessa forma, as análises podem levar em conta uma série de fatores, dentre os quais: o tempo de fixação do olhar, a quantidade de fixação, a extensão das sacadas e a quantidade de regressões efetuadas.

Outra técnica recorrente, o teste de aceitabilidade, é off-line e envolve o uso de escala. A mais comum é a escala Likert, que pode possuir cinco ou sete alternativas. Ao/À participante é solicitado que avalie uma determinada passagem apresentada por escrito, segundo aquilo que ele/a considera mais aceitável. Dessa forma, o/a pesquisador/a obtém um resultado pós-processamento, cujo foco está em uma interpretação feita pelo/a participante, em um julgamento consciente de determinado aspecto (SCHÜTZE; SPROUSE, 2013; SOUZA; FRANZEN; SCHLINCHTING, 2019). Nas pesquisas discutidas neste artigo, as sentenças-alvo apresentadas aos/às participantes possuem retomadas anafóricas realizadas de formas distintas, permitindo ao/à pesquisador/a pontuar o grau de aceitabilidade de cada sentença e comparar se houve diferenças e quais são elas. Em um dos estudos analisados, o de Milhorance (2014), a técnica foi nomeada como julgamento de gramaticalidade, face ao problema e aos fundamentos da pesquisa, não tendo havido, entretanto, alterações na forma de elaboração, aplicação e análise da técnica.

\section{O Que as Pesquisas sobre Processamento Anafórico Têm Evidenciado?}

O laço comum que une os trabalhos encontrados está no fato de que todos buscam compreender o funcionamento da anáfora. São diferentes realizações anafóricas e distintos contextos em que os trabalhos buscam, dentro de suas respectivas especificidades, entender como esse importante recurso de coesão atua

\footnotetext{
${ }^{10}$ Como demonstrado no Quadro 1, a técnica de leitura automonitorada é empregada nos estudos 1, 2, 3, 4, 6, 7, 9, 10, 12 e 14. O teste de aceitabilidade, por sua vez, é utilizado nos estudos 1, 7, 8 e 11. Por fim, a técnica de rastreamento ocular é utilizada nos estudos 5 e 7 .
} 
cognitivamente. É possível dizer que, de modo geral, o foco dos trabalhos está em investigar como diferentes formas de realizar uma anáfora podem influenciar nos custos para o processamento e como fatores sintáticos e semânticos contribuem no processamento dessas diferentes anáforas. Muitos estudos (QUEIROZ, 2009; LEITÃO; SIMÕES, 2011; MAIA, 2013; TEIXEIRA, 2013; SIMÕES, 2014) buscam, sobretudo, pelas diferenças entre anáforas realizadas com pronomes, com a repetição do nome (do antecedente) e com o nulo. Junto a essas formas de retomada, são combinadas outras variáveis, a fim de investigar quais fatores, além do tipo da anáfora propriamente dito, podem contribuir nos custos no momento da leitura.

O estudo do processamento anafórico, em suas mais distintas vertentes, considerando diferentes variáveis, é essencial para subsidiar aspectos dos planejamentos e implementação do ensino da leitura. Como apresentado inicialmente, a anáfora tem papel fundamental na coesão textual. A partir desse recurso, é possível promover a continuidade temática, desenvolver e organizar as ideias de modo a articular as diferentes partes de um texto, garantindo a tecitura do todo textual (HALLIDAY; HASAN, 1976). Nesse sentido, as diferentes pesquisas ora relatadas podem trazer luz às implicações cognitivas, geradas pelas diferentes formas de se construir essa amarração interna ao texto.

Queiroz (2009), Leitão e Simões (2011) e Correia (2014) confirmam, em suas investigações, a penalidade do nome repetido, isto é, a repetição do antecedente gera mais custos no momento da leitura, quando comparada à anáfora realizada com o pronome. Nesses estudos, isso ocorre quando a anáfora está na posição de sujeito (QUEIROZ, 2009), em diferentes distâncias do antecedente (LEITÃO; SIMÕES, 2011) e na posição de objeto (CORREIA, 2014). No que tange à penalidade do nome repetido, no estudo de Milhorance (2014), os/as falantes do PB avaliam como mais aceitáveis as frases com construções anafóricas elípticas em contextos como: "O Leandro sonhou com alguma atriz da Globo, mas eu não sei com quem [teandrosenhou]". Ou seja, as construções nas quais houve a repetição não foram bem avaliadas pelos/as leitores/as. A pesquisadora relaciona esse resultado à penalidade do nome repetido, ou seja, em um contexto tão próximo, os custos para o processamento se tornam maiores quando ocorre a repetição, por isso a elipse seria mais bem avaliada. Claro que, aqui, trata-se de uma avaliação consciente, feita por meio da técnica de julgamento de gramaticalidade/aceitabilidade, e o contexto investigado é completamente diferente daqueles que confirmam a penalidade. No entanto, traz subsídios que podem ajudar a refletir sobre o processamento de retomadas no momento da leitura.

Há que se considerar, ainda, a distância entre antecedente e anáfora. Leitão e Simões (2011) trabalham com frases cuja distância entre antecedente e anáfora é curta (entre 10 e 14 sílabas), média (entre 24 e 28 sílabas) e longa (entre 34 e 38 sílabas), mas em todas as condições o pronome lexical foi processado mais rapidamente que o nome repetido. De acordo com Kintsch e Rawson (2013, p. 233), os pronomes tendem a ser usados em referência a antecedentes mencionados de modo mais recente, enquanto as anáforas explícitas, como a repetição do nome, acabariam por atrasar o processamento em condições nas quais o antecedente esteja muito saliente ou explícito. Parece ser o caso em Leitão e Simões (2011). Mesmo a distância longa, de 38 sílabas, não foi suficiente para que a repetição do nome fosse processada sem maiores custos. A repetição do nome pode representar menos custos para o processamento em porções textuais maiores. Mas, em contextos sentenciais menores, o antecedente ainda está bastante ativo na memória do/a leitor/a; assim, sua repetição acaba sobrecarregando o processamento. A seu turno, Correia (2014) trabalha com uma população distinta das outras pesquisas citadas, investigando pessoas que gaguejam e que, por conta dessa condição, teriam a memória procedimental afetada; no entanto, o estudo não mostra diferença nos custos de processamento entre pessoas que gaguejam e pessoas que não gaguejam. Além disso, a investigação corrobora a penalidade do nome repetido em ambas as populações.

Ao refletir sobre os tipos de retomadas anafóricas que são processadas mais rapidamente e em quais contextos tais retomadas são favorecidas, Maia (2013) demonstra que ocorre um processamento mais rápido 
para os pronomes nulos que retomam antecedentes salientes. No entanto, o experimento realizado por Maia sugere um processamento mais rápido dos nomes repetidos do que dos pronomes plenos, diferentemente do que mostram os estudos citados no parágrafo anterior. Assim, o autor descarta a penalidade do nome repetido e constata uma penalidade do pronome pleno. ${ }^{11} \mathrm{O}$ que o pesquisador verifica, a partir dos experimentos realizados, é que a saliência do antecedente não gera efeito significativo para o processamento de pronomes ou nomes repetidos. Apenas o processamento do pronome nulo é favorecido pela saliência sintática ${ }^{12}$ e penalizado em condições de antecedente não salientes. $\mathrm{O}$ uso da técnica de rastreamento ocular corrobora tais resultados. Teixeira (2013) ratifica esses resultados ao investigar as preferências sintáticas para o processamento de pronomes plenos e nulos. Os dados mostram que, em estruturas ambíguas, os/as leitores/as relacionam o pronome nulo ao sujeito da sentença. Já os pronomes plenos não se mostraram aptos a resolver o problema da ambiguidade apresentado no teste experimental. Nessa etapa da pesquisa, os resultados revelaram haver um tempo maior de reação para a leitura das condições com o pronome pleno se comparadas às condições com o pronome nulo. É preciso ponderar, contudo, acerca do fato de as condições experimentais entre os estudos serem distintas, o que pode gerar essa diferença nos resultados.

Nesse sentido, Gondim (2017) leva em conta as diferenças metodológicas nas pesquisas e realiza experimentos para entender em quais condições a penalidade do nome repetido acontece no Português Brasileiro. A partir dos resultados encontrados, a pesquisadora chega à conclusão de que, para que a penalidade do nome repetido seja constatada em $\mathrm{PB}$, é necessário considerar um conjunto de fatores linguísticos e metodológicos, sendo, portanto, um efeito multifatorial em que a forma de segmentação/aferição do tempo do conjunto experimental é o principal fator de influência, além da quantidade de antecedentes humanos possíveis de serem retomados. Assim, o que a pesquisadora encontra é a existência de penalidade do nome repetido em PB entre pronome e nome repetido a depender da configuração experimental. Os resultados sugerem, portanto, que o custo para o processamento da anáfora varia conforme as condições apresentadas ao/à leitor/a. Isso explicaria a diferença encontrada nos trabalhos anteriores, que foram realizados a partir de material experimental distinto, e mostra a importância das escolhas experimentais no momento de realizar um estudo. Com esses resultados, vê-se também que, a depender das escolhas feitas para construir a progressão referencial, o pronome pleno pode ser considerado como um elemento que gera maior ou menor carga de processamento, e isso independe da sua natureza.

Outro ponto abordado nos estudos está nas preferências semânticas no processamento da anáfora (TEIXEIRA, 2013). Nesse sentido, são testadas anáforas em relação de hiponímia e de hiperonímia. Os resultados mostram que o custo de processamento da anáfora em relação de hiperonímia com seu antecedente tende a ser mais baixo que o da anáfora em relação de hiponímia, quando em posição de sujeito. A diferença entre hiperônimo e hipônimo na posição de objeto não foi significativa. Essa constatação leva a uma discussão sobre a distância semântica entre antecedente e retomada e os custos para a memória de trabalho. Trata-se de importante questão a ser ponderada no momento que se sai do laboratório experimental e se passa a considerar a leitura em si, pois os fatores que geram mais custos para o processamento podem, em determinadas situações, comprometer a compreensão leitora. Então, para além das discussões em torno de aspectos cognitivos envolvidos no processamento anafórico, cabe refletir sobre as consequências dessas penalidades reportadas pelos estudos para a leitura de porções textuais maiores, especialmente no que diz respeito à construção das inferências, possibilitada, também, pelas retomadas anafóricas (KINTSCH; RAWSON, 2013).

\footnotetext{
${ }^{11}$ Lezama (2008) estudou o processamento, na língua espanhola, de anáforas realizadas com pronomes plenos, pronomes nulos e nomes repetidos. Resumidamente, o autor constatou, em anáforas que retomam antecedente em posição de sujeito, uma penalidade que denominou de overt pronoun penalty (ou penalidade do pronome pleno).

12 Antecedente em posição de sujeito.
} 
Dentre os estudos que retornaram com o levantamento há, ainda, aqueles que centram seus esforços em compreender o funcionamento de outros tipos de realizações anafóricas e, também, o contexto (semântico e sintático) em que as anáforas são realizadas (LEITÃO, 2010; BEZERRA; LEITÃO, 2013; HENRIQUE, 2016; ARAÚJO, 2017). Leitão (2010) trabalha com o efeito de paralelismo, relacionando-o à animacidade do antecedente em retomadas anafóricas feitas pelo pronome na posição de objeto. Talvez a principal constatação feita a de seja que fatores estruturais são atuantes no processamento anafórico, inclusive o pronominal (diferente do que trazem algumas teorias - HANKAMER; SAG, 1976; SAG; HANKAMER, 1984, citadas por LEITÃO, 2010 -, para as quais apenas fatores semânticos atuariam no processamento pronominal). Assim, a estrutura da sentença pode contribuir para que determinado referente fique ativo na memória de trabalho e seja recuperado mais facilmente. Vale considerar que a leitura é uma atividade cognitiva complexa, que envolve diversas subtarefas, dentre elas o estabelecimento adequado da correferência, isto é, para que o/a leitor/a possa compreender o sentido do que está sendo lido, é primordial que, ao se deparar com uma anáfora, seja encontrado o antecedente adequado. Tudo isso deve ser feito muito rapidamente, a partir das informações que estão ativas na memória de trabalho. O que se percebe dos resultados até então apresentados é que existem elementos e estruturas que são mais favoráveis a essa ativação rápida. Contudo, há que se considerar também a capacidade de memória de trabalho do indivíduo participante da pesquisa.

Bezerra e Leitão (2013) investigam a diferença de processamento nas anáforas realizadas por pronomes que são argumentos e nas que são adjuntos de núcleos verbais e de núcleos nominais. ${ }^{13}$ Os resultados mostram que a leitura das anáforas que são argumentos de núcleos nominais é mais rápida que a de adjuntos. Quanto aos núcleos verbais, a pesquisa não identificou diferenças significativas. Resultados como esse trazem indícios de que há muitos fatores que podem ser considerados quando se trata de processar a anáfora durante a leitura. Há, também, quem olhe para o processamento de outros tipos de anáforas, tal como Henrique (2016), que estuda anáforas reflexivas: a si mesmo e se. A autora realizou um teste de aceitabilidade dessas duas formas de retomada. A anáfora construída com o "se" foi a considerada mais aceitável dentro do contexto investigado. Uma das principais constatações obtidas está no fato de que "não só a posição da anáfora nas sentenças é suficiente para que o predicado se torne reflexivo, mas que seu traço semântico atua na interpretação de sentenças reflexivas" (p. 76).

A anáfora a si mesmo é investigada também por Correia (2014), já que a realização dessa anáfora se dá de modo intrassentencial e, por isso, estaria mais exposta a princípios gramaticais, os quais poderiam gerar algum custo maior para o processamento de pessoas que gaguejam. ${ }^{14}$ Assim, nesse experimento, o objetivo foi examinar o tempo de leitura da anáfora a si mesmo/ a precedida por um antecedente gramatical e um agramatical. ${ }^{15}$ O experimento mostrou que os/as falantes que não possuem gagueira são mais rápidos na condição gramatical e mais lentos na condição agramatical. As pessoas que gaguejam, por sua vez, apresentam padrão oposto, embora os resultados não sejam significativos. Nesse sentido, uma das hipóteses ${ }^{16}$ aventadas na pesquisa é corroborada e, ainda, há uma indicação de que a memória procedimental tem influência sobre as habilidades

\footnotetext{
${ }^{13}$ Exemplos: argumento de núcleo verbal - “Os policiais abordaram o malandro no bar. Lutaram com ele no local.”; adjunto de núcleo verbal - "Os policiais abordaram o malandro no bar. Demoraram com ele no local.”; argumento de núcleo nominal - "Os policiais abordaram o malandro no bar. Efetuaram a prisão dele no local.”; adjunto de núcleo nominal - "Os policiais abordaram o malandro no bar. Recolheram a munição dele no local”.

${ }^{14}$ Público investigado em Correia (2014).

15 O exame seguiu, com base em Chomsky (1981,1986), o princípio A da Teoria da Ligação, a qual compreende que anáforas (que são os reflexivos e recíprocos) devem estar ligadas em seu domínio de ligação (LEITÃO, 2005).

${ }^{16}$ Uma das suposições da pesquisadora é a de que, se os princípios que atuam nas correferências intrassentenciais "estão radicados na memória procedimental e essa memória está enraizada nas estruturas cerebrais que apresentam alterações neurais nas PQG [pessoas que gaguejam], podemos esperar que estas pessoas evidenciem um desempenho atípico no processamento dessa forma de correferência, já que supomos estarem esses princípios de ligação correlacionados com a gramática e a gramática com a memória procedimental.” (CORREIA, 2014, p. 31-32).
} 
gramaticais das pessoas que gaguejam, por isso o processamento de anáforas intrassentenciais é diferente entre os grupos. Essa diferença não é encontrada em anáforas correferenciais intersentenciais. Com isso, entende-se que, em anáforas correferenciais intersentenciais, a memória de trabalho tem um papel mais ativo do que a memória de procedimento.

Dentre os estudos das anáforas reflexivas está o de Araújo (2017), que investiga as seguintes anáforas: ele/a mesmo/a e ele/a próprio/a. O autor busca comprovar o Princípio A da Teoria da Ligação de Chomsky, mostrando que tais anáforas atuam de acordo com o que se espera de uma anáfora nessa teoria e, portanto, retomam antecedentes que estão disponíveis em seu domínio de ligação (ou seja, estão na própria oração), sendo os indisponíveis restringidos no primeiro momento do processamento. Isso se confirma nos experimentos realizados na investigação. Assim, em construções como: "João disse que José machucou ele mesmo/ele próprio no parque de diversão.", o/a leitor/a relaciona a anáfora a "José" e não a "João", sendo que, em condições em que o/a leitor/a é forçado a relacionar tal anáfora ao primeiro antecedente (como em: "Maria disse que João machucou ela mesma no parque de diversão"), os tempos de leitura do segmento crítico são maiores.

Embora todos os trabalhos até aqui discutidos usem estímulos escritos em seus experimentos (o que implica a ação de leitura), nenhum deles se atém às teorias em torno da leitura em si. Cunha-Lima (2004), por sua vez, embora não trabalhe com textos em seu experimento, reflete sobre o papel da anáfora nos processos de leitura. Essa pesquisadora buscou investigar em quais contextos uma expressão nominal indefinida poderia ter uma leitura anafórica. ${ }^{17}$ Os resultados obtidos com o experimento reafirmam o fato de a expressão nominal não ter seu valor estabelecido somente no momento do seu processamento, mas, também, a depender do verbo e dos eventos expressos na sentença. O que a pesquisadora percebe é que o indefinido é menos informativo e muito sensível ao contexto. Os resultados indicam que o indefinido somente será anafórico quando não for argumento de nenhum verbo finito que expresse um evento diferente daquele introduzido pelo antecedente. Esses achados podem, também, ser relacionados aos custos para a memória de trabalho. Ao encontrar uma expressão indefinida aliada a um verbo, o/a leitor/a interpreta como uma informação nova (um novo evento) e, dentro do contexto das sentenças apresentadas, a informação nova pode não fazer sentido ou, então, requerer a manutenção de um conjunto maior de informações para que o sentido possa ser inferido na continuidade da leitura. Há que se considerar que a interpretação anafórica é feita com um candidato referencial que esteja ativo. ${ }^{18}$ Assim, evita-se criar outros referentes sem necessidade, economizando recursos cognitivos de memória e favorecendo o processamento.

Seguindo em uma perspectiva que considera a anáfora no contexto de recepção escrita, Cavalcante (2017) investiga a influência da correferência anafórica e do humor na compreensão leitora. De todos os estudos encontrados, este é o único que trabalha com textos ${ }^{19} \mathrm{em}$ seu desenho experimental. A pesquisadora não tem por foco formas de realizações anafóricas específicas tampouco considera questões semânticas e sintáticas que poderiam influenciar no processamento. O esperado era que textos com anáforas correferenciais e com humor favorecessem a compreensão dos/as participantes. Não foi possível, no entanto, validar tal hipótese a partir dos resultados obtidos. Isso pode ter ocorrido em decorrência de diversos fatores inerentes à investigação. No estudo de Cavalcante, a forma de realização da anáfora não foi considerada. A pesquisadora

\footnotetext{
${ }^{17}$ São exemplos de sentenças com as quais Cunha-Lima trabalhou: Indefinido e frase nominal - "Meu gato caçou um rato. Um rato grande e gordo"; definido e frase nominal - "Meu gato caçou um rato. O rato grande e gordo"; indefinido e verbo finito - "Meu gato caçou um rato. Um rato correu porta a fora"; definido e verbo finito - "Meu gato caçou um rato. O rato correu porta a fora" (CUNHALIMA, 2004, p. 188).

${ }^{18}$ Essa ativação pode ser propiciada por diferentes fatores morfológicos, sintáticos, semânticos e discursivos.

${ }^{19}$ Considerando a concepção de texto, em perspectiva dialógica, segundo a qual um texto é o lugar da interação, e os interlocutores são atores sociais ativos e dinâmicos que no texto se constroem e são construídos (KOCH, 2006; MARCUSCHI, 2008).
} 
apenas evitou o trabalho com a referência nula. O que a pesquisa concluiu é que a compreensão textual se dá por meio da operação desses processos (correferência anafórica e humor), mas não da forma esperada e apresentada nas hipóteses. Os resultados da investigação abrem portas para muitas discussões em torno do papel da anáfora correferencial no processamento de um texto. É possível que, ao se juntar o que os outros estudos ora apresentados levantam em torno da anáfora, tenhamos mais subsídios para avaliar como a anáfora atua no processamento e como as relações anafóricas intratextuais podem ser ensinadas na atividade de leitura. Não basta que haja relações anafóricas em um texto e que elas sejam reconhecidas. A depender dos propósitos que se tem ao escrever e ao ler um texto, é necessário que essas relações sejam realizadas de modo a considerar seu processamento. A ausência dessa consideração pode elevar os custos para a compreensão, dificultando a produção de sentidos.

Ao analisar cada um dos estudos reportados neste artigo, é possível perceber que, de acordo com as escolhas feitas, o custo para o processamento pode ser maior ou menor. Tanto o uso do nome repetido quanto o uso de hiperônimo ou mesmo a forma como a construção das sentenças é realizada podem exigir mais da memória de trabalho do/a leitor/a, o que eleva o tempo de processamento. A memória de trabalho é um recurso cognitivo fundamental no processamento do texto escrito, pois atua armazenando temporariamente uma informação recém recebida e fazendo a manipulação dessa informação de sorte a tecer o fio textual. Assim, a partir do todo ora apresentado, entende-se que os resultados obtidos pelos estudos revelam aspectos importantes sobre a relação entre memória de trabalho e processamento anafórico, sendo possível inferir implicações para a compreensão leitora e para o seu ensino. Afinal, o processamento no nível microestrutural gera implicações na representação mental de um texto lido (KINTSCH; RAWSON, 2013). O estabelecimento da anáfora atua em um determinado nível da compreensão leitora (GAGNÉ; YEKOVICH; YEKOVICH, 1993), mas se mostra integrado a outros níveis, como o parseamento e o acesso lexical, que, por sua vez, se relacionam diretamente à capacidade de memória de trabalho. E tudo isso pode e deve ser considerado quando ensinamos leitura em sala de aula.

\section{Implicações Pedagógicas: como esses estudos podem CONTRIbuir Para o ENSINO DA LEITURA?}

A partir do mapeamento apresentado dos estudos que investigam o processamento anafórico, podemos construir pontes e tecer discussões para o ensino da leitura. Afinal, todas essas investigações realizadas em laboratório têm como grande intuito compreender mais e melhor o funcionamento da língua e, de modo específico, como o processamento cognitivo acontece mediante determinadas realizações linguísticas. Esses estudos nos oferecem recursos e resultados que podem - e devem - subsidiar a prática pedagógica. No que nos interessa em particular - razão que justifica o recorte dos estudos incluídos na revisão sistemática -, importa saber como ocorre o processamento da anáfora em estímulos de natureza escrita e em atividades de leitura, a fim de ponderarmos e discutirmos as implicações pedagógicas para o ensino desta tão complexa competência que o ato de ler requer.

O ensino da leitura pode partir de diferentes abordagens metodológicas. Se se pretende bem-sucedido, todavia, precisa considerar de modo indissociado fatores linguísticos, textuais, desenvolvimentais relativos à aprendizagem, (meta)cognitivos e sociais ou culturais (FLOOD, 1984; RUDDELL; RUDDELL; SINGER, 1994; KAMIL et al., 2011; ALVERMANN; UNRAU; RUDDELL, 2013; SNOWLING; HULME, 2013). Partindo do pressuposto de que leitura não é uma competência adquirida naturalmente em contextos de imersão e interação e de que sua aprendizagem requer prática planejada, fundamentada e sistematizada (McGUINNESS, 2006; SOUZA; GARCIA, 2012; SOARES, 2016), há que se considerar aspectos relativos ao sujeito da aprendizagem - neste caso o/a leitor/a em formação -, ao/à(s) profissional(is) que assume (m) o 
ensino - neste caso o/a(s) professor/a(es) $-{ }^{20}$ ao texto, que é o objeto da leitura, sem o qual a atividade não pode ser realizada, e ao contexto e à situação de aprendizagem (ALLIENDE; CONDEMARÍN, 2005; RUDDELL; UNRAU, 2013; HEINIG, 2019). Especialmente considerando o que abarca o escopo deste estudo, por limitações que se impõem a toda e qualquer pesquisa, interessa-nos a reflexão acerca de dois desses fatores em particular: o texto e a sua constituição linguística interna, especialmente a correferenciação, e o/a leitor/a, singularmente no que diz respeito ao aspecto cognitivo de processamento.

A discussão ora proposta é fruto de trabalho em que se pondera, sobretudo, sobre a natureza do objeto de ensino e sua composição - o texto - e de como o seu conhecimento pelo/a professor/a possibilita a elaboração de propostas e projetos pedagógicos que consideram e exploram as características dele provenientes, já que o texto é o estímulo verbal com base no qual a leitura toma seu lugar. Ademais, reflete, ainda, sobre a relação que o/a leitor/a, no ativo e dinâmico processo de produção de sentidos a partir do escrito, estabelece com o texto relação que é modulada por fatores relativos ao próprio sujeito que lê e à sua condição leitora, ao ambiente e - tão importante quanto os demais - ao modo como o texto é tecido e composto. Tal como propõem Seimetz-Rodrigues e Souza (2016), destacar aspectos concernentes à

superfície textual, bem como reconhecer que a compreensão também depende de fatores que dizem respeito ao conhecimento prévio do leitor, aos objetivos e às condições da leitura, eì assumir uma perspectiva integrativa do processo de leitura, segundo a qual a compreensão eì produto da integração entre elementos do texto e do leitor, ainda que ela ocorra de modo a que uma das pontas permaneça estática: o texto, e a outra provoque toda a dinâmica e dê vida e luz aos sentidos: o leitor. Portanto, a consequência necessária dessa assunção é a de que proposições de práticas pedagógicas para o ensino da leitura, a fim de resultarem eficazes, requerem a consideração dos fatores provenientes do texto - o objeto de ensino - assim como os provenientes do leitor - o aprendiz. Ou seja, requer compreender que tipo de demanda o objeto de ensino coloca sobre o aprendizleitor e, em contrapartida, que tipo de demanda o encontro das características individuais do sujeito com as características do objeto de ensino coloca sobre quem ensina (p. 63).

É fato que, embora o ensino do sistema de escrita e das habilidades de decodificação seja necessário e fundamental para ensinar a ler, ele não é suficiente (SOLÉ, 1998; SEIMETZ-RODRIGUES; SOUZA, 2016) - ou, pelo menos, não o é quando se está colocando em questão o ensino de leitura a quem já é leitor/a iniciado/a. Daí ser requerido, também, que sejam ensinados aspectos ligados a níveis mais elevados de compreensão, aqueles que ultrapassam a unidade da palavra e as relações internas básicas constitutivas das frases. A resolução adequada e a compreensão das anáforas se inserem nesse ponto, porque, primeiro, ao reconhecer que um determinado elemento do texto é retomado de diferentes formas, tem-se, a partir das pistas textuais, a possibilidade de compreender o assunto do texto, integrar os diferentes pontos que tratam desse assunto e, então, chegar à sumarização (OAKHILL; CAIN; ELBRO, 2017; SOUZA; SEIMETZ-RODRIGUES; WEIRICH, 2019), formando uma representação mental possível de ser relacionada ao conhecimento prévio do/a leitor/a e, assim, produzindo sentido. Mas como o ensino de leitura pode se pautar nos dados de processamento das anáforas?

Dos trabalhos apresentados, Cavalcante (2017) é o único que busca investigar a relação entre o processamento anafórico e a compreensão em leitura de modo direto. Como já discorrido, uma das hipóteses apresentadas pelo estudo é a de que textos com anáforas correferenciais são compreendidos com mais facilidade pelo fato de terem essas retomadas. Sabemos que, de fato, as anáforas correferenciais são importantes elementos

\footnotetext{
${ }^{20}$ Mesmo não se tratando do foco do estudo apresentado neste artigo, consideramos fundamental esclarecer que assumimos perspectiva segundo a qual o ensino da leitura é papel da escola de educação básica e deve ser compromisso de todas as áreas do conhecimento (NEVES et al., 2011; SOUZA; BACK; FINGER-KRATOCHVIL, 2012). Ressalva-se, todavia, por razões relativas à especificidade do sistema de escrita e do seu processo de aprendizagem, que a alfabetização seja assumida por profissional com aprofundado conhecimento para o ensino inicial da leitura e da escrita (SOUZA; JUNKES, no prelo).
} 
de coesão que auxiliam na progressão sequencial. Nesse sentido, atuam como recursos que auxiliam na construção de uma representação mental coerente (KINTSCH; RAWSON, 2013; KOCH; ELIAS, 2015; OAKHILL; CAIN; ELBRO, 2017; SOUZA; SEIMETZ-RODRIGUES; WEIRICH, 2019). A investigação realizada por Cavalcante (2017), no entanto, não apresenta dados suficientes para validar essa hipótese, o que nos leva para os resultados encontrados nos outros estudos, que consideram diferentes fatores ao estudarem o processamento anafórico. Isto é, não basta apenas a retomada de um antecedente para que a compreensão esteja garantida, pois, a depender de como essa retomada é construída, os custos para o processamento podem ser elevados e, consequentemente, podem dificultar os processos de compreensão, por terem implicações que remetem à capacidade e ao funcionamento da memória de trabalho. Ao se operar com a integração e a sumarização de um texto, é importante considerar o papel das anáforas correferenciais como pistas textuais que garantem a progressão do texto, mas é importante, também, pensar na forma como elas são realizadas e construídas. Como é feita a retomada do antecedente? Qual a construção sintática em que retomada e antecedente se encontram? Quais as informações semânticas que estão disponíveis? São perguntas a serem levadas para o ensino, a fim de que se possa destrinchar tais aspectos nos textos trabalhados em sala de aula.

Alguns dos estudos reportados (QUEIROZ, 2009; LEITÃO; SIMÕES, 2011; CORREIA, 2014) mostram, por exemplo, que a repetição do antecedente (o nome repetido) eleva os custos do processamento, ao menos em contextos nos quais a distância entre antecedente e anafórico é curta. Isso significa que, cognitivamente, quando encontramos a repetição de um antecedente ainda ativo em nossa memória, levamos mais tempo para processá-lo. Maia (2013), por sua vez, mostra que, em contextos sentenciais específicos nos quais a anáfora retoma antecedentes salientes, o pronome nulo pode gerar custos menores. Todas essas evidências sugerem que o trabalho com a leitura precisa ter fundamentos pautados também na organização sintática e semântica da língua. Nesse sentido, conhecer, discutir e saber usar a sintaxe e os diferentes "marcadores de coesão no nível linguístico" (KINTSCH; RAWSON, 2013, p. 228) ou as diferentes formas de retomada, pode garantir a construção das inferências conectivas e de preenchimento de lacunas e, por consequência, participar de um processamento mais rápido, preciso e com menores custos para a memória de trabalho.

Verifica-se, de modo geral, que, para leitores/as experientes, as formas anafóricas menos custosas são aquelas que possuem menos informações semânticas, especialmente se o antecedente a ser retomado está em posição de destaque (saliência ou foco estrutural). Assim, o que se depreende é que a automatização gera um fluxo contínuo em que a memória de trabalho opera de modo a relacionar a pouca informação semântica da retomada ao item em destaque, foco do que está discorrendo o texto lido. Se a relação não se der com o item em destaque, provavelmente o custo de processamento será aumentado, pois o/a leitor/a precisa parar a leitura para encontrar o antecedente correto, o que interfere no tempo e, consequentemente, na compreensão. Por outro lado, se o texto apresenta um elemento com mais informações semânticas, é esperado que haja um objetivo para isso - leitor/a e texto estabelecem uma esperada relação de parcimônia -, e maiores recursos de memória podem ser alocados a fim de realizar tal processamento a contento.

De acordo com Perfetti, Landi e Oakhil (2013, p. 255), “as dificuldades de compreensão podem estar localizadas em pontos de elevada demanda de processamento, sejam de fontes sintáticas ou de outra forma”. Nesse sentido, um trabalho sistematizado de ensino de leitura que toque nos aspectos de retomada, considerando as diferentes construções anafóricas a serem realizadas, pode auxiliar a não sobrecarregar o sistema de memória de trabalho, garantir a velocidade de processamento e otimizar as possibilidades de compreensão, o que é positivo à aprendizagem. Ou seja, desautomatizar essas diferentes construções, aprender a lidar com elas para, então, novamente automatizá-las é um dos meios que pode conferir a rapidez e a acurácia que a leitura fluente requer. Exemplo de trabalho que visa tal desautomatização é o proposto por Souza, Seimetz-Rodrigues e Weirich (2019), no qual sugerem a implementação de roteiros de leitura, a fim de 
avaliar processos e desempenhos e de desenhar planejamentos instrucionais que tenham por foco a exploração do texto na relação com os conhecimentos prévios do/a leitor/a em uma determinada situação de leitura. Especialmente no roteiro 1, que visa ao ensino de leitura, as autoras focam em aspectos de coesão, na microestrutura do texto, demonstrando o papel das relações entre os elementos na construção da teia textual e, também, na compreensão do lido.

Além disso, estudos relatados por Perfetti, Landi e Oakhil (2013, p. 256) mostram que as dificuldades com a sintaxe podem mascarar um problema "alojado" na capacidade da memória de trabalho, porque "entender uma sentença envolve lembrar-se das palavras que a compõem, recuperar informações do texto antecedente, analisar a sentença e outros processos que demandam recursos". Por que, então, se relacionam de modo tão direto os resultados obtidos nessas mais diversas pesquisas apresentadas com o ensino sistematizado e a aprendizagem da leitura? Ora, conforme já anunciado, o estabelecimento da correferência é um processo que implica conhecimento linguístico específico para a compreensão do que se lê, faz parte do conhecimento conceitual e procedural, ou seja, é condição fundamental para a relação que o/a leitor/a estabelece com o texto (SOUZA; SEIMETZ-RODRIGUES; WEIRICH, 2019). Quanto mais experiência e conhecimento o/a leitor/a tiver em torno dos aspectos envolvidos no estabelecimento da correferência, menores serão os custos para o processamento e mais facilmente a compreensão poderá ser estabelecida, pelo menos no que compete a este aspecto.

Pensar nas diferentes formas de realizar uma anáfora, na estrutura sintática em que ela é construída e nas relações semânticas existentes tem se mostrado primordial para compreender como a cognição atua diante dessas diferenças. E conhecer tais aspectos em perspectiva psicolinguística, considerando o processamento das informações com vistas à compreensão, traz importantes implicações à prática pedagógica. Resolver uma anáfora de forma adequada significa dar coesão ao tex to e, por sua vez, dar coesão ao texto significa compreender as relações estabelecidas entre as diferentes porções textuais, garantindo o processamento das informações e a articulação com aquilo que previamente o/a leitor/a já sabe, o que cria condições para o estabelecimento da coerência e de produções de sentido que sejam relevantes e autorizadas pelo texto. Nesse aspecto, a memória de trabalho exerce papel fundamental, pois, sendo a compreensão da linguagem uma forma de pensamento complexo, é necessário que haja o processamento sequencial de elementos, com a retenção temporária das informações para que outros processos concomitantes e fundamentais para a compreensão continuem ocorrendo (decodificação, integração, reflexão...) (SOUZA, 2004).

Assim, quando entendemos que: i) durante a leitura de um texto, o processamento menos custoso de anáforas reflete na representação mental que o/a leitor/a produz daquele texto; e ii) o processamento da anáfora com menores custos depende de fatores morfológicos, sintáticos, semânticos e da escolha feita para realizar a retomada, defendemos, assim como o fazem outros pesquisadores, que o ensino da leitura deve passar pela reflexão desses fatores. Cabe, desse modo, refletir com os alunos sobre como a correferenciação se estabelece nos textos lidos, sobre o porquê de determinado referente não ser sempre repetido da mesma forma toda vez que é retomado e discutir, ainda, quais formas parecem mais adequadas para que ele seja retomado dentro de um determinado texto - reflexões estas que participarão do processo de formação não apenas para a leitura, mas também para a escrita. Ou seja, é necessário que se busque pensar sobre a língua a fim de, como já destacamos, desautomatizar determinados processos para, após terem sido compreendidos e aprendidos, automatizá-los. Compreender, portanto, as restrições que subjazem às diferentes formas anafóricas utilizadas e os mecanismos cognitivos envolvidos no processamento da anáfora é um passo importante para pensar na compreensão da linguagem e, consequentemente, na compreensão em leitura e no seu ensino. 


\section{Considerações Finais}

Esta revisão sistemática em torno do processamento anafórico em tarefas de leitura teve por objetivos: mapear o que se tem pesquisado acerca da temática, e como as pesquisas vêm sendo conduzidas, e propor ponderações sobre as implicações pedagógicas para o ensino da leitura. Quanto ao foco, os estudos investigam, cada um a seu modo e em respeito aos seus objetivos, quais anáforas geram mais custos para o processamento e em quais contextos sentenciais, utilizando-se de delineamentos experimentais, por meio das técnicas de leitura automonitorada, rastreamento ocular e julgamento de aceitabilidade, o que reforça a índole explicativa e a tradição experimental da psicolinguística (PINTO, 2019). Diante do que foi apresentado a respeito dos estudos, três pontos, sobre os quais versarão estas considerações, se mostram centrais no que tange a reflexões sobre o objeto aqui investigado, a saber: a atuação da memória de trabalho, o papel da anáfora na compreensão textual e as relações entre os resultados obtidos experimentalmente e o ensino de leitura.

Segundo o que discutem as pesquisas, a memória de trabalho exerce relevante papel no processamento da anáfora, já que sua compreensão requer a manutenção e a manipulação do antecedente na e pela memória, a fim de que possa ser estabelecida adequadamente a relação entre o elemento anafórico e seu referente no texto. Muitas das pesquisas aqui apresentadas trazem argumentos que evidenciam o quanto a memória de trabalho e os custos envolvidos no processamento anafórico estão relacionados. Apesar da constante articulação feita nas discussões dos dados, a memória de trabalho não é considerada variável nas investigações analisadas, tampouco recebe qualquer tipo de controle. Nesse sentido, conclui-se que existe a necessidade de que ela seja considerada uma variável de pesquisa, cruzando capacidade individual de memória, tempo de leitura da anáfora e acurácia, a fim de se identificar em que medida este sistema de memória participa do processamento da anáfora, tornando-o mais ou menos eficiente e dispendioso cognitivamente, em conjunto com outros fatores que as pesquisas estão controlando, tais como tipo de anáfora e distância (espacial, sintática e semântica) entre anáfora e antecedente. Ademais, considerar a memória de trabalho como uma variável de pesquisa pode trazer esclarecimentos sobre o seu papel na compreensão em leitura de textos, que passa necessariamente (embora não exclusivamente) pelo processamento da correferência.

A despeito do fato de que se leem textos, por razões que passam pelo controle experimental e pela natureza das tarefas empregadas, a maioria das pesquisas que estudam o processamento anafórico tem por foco o nível sentencial. Isso se justifica não apenas pelas tarefas e pelo controle, mas também porque a anáfora atua na construção da microestrutura textual, que precisa ser formada para que se alcance a macroestrutura e se possa, assim, criar uma representação mental em torno do que está sendo lido. Com isso, não se está defendendo que a compreensão aconteça de modo linear, mas, sim, que há alguma linearidade nos processos, ao mesmo tempo em que há ativação disseminada e paralela e em que a produção de sentidos e o levantamento de hipóteses vai tomando seu lugar na representação mental do texto. Desse modo, embora a maioria das pesquisas não toque na compreensão textual em si, entende-se que a relação acontece intrinsecamente pela natureza do tecido do texto. E, por essa razão, mostra-se relevante discutir a relação e o papel do processamento anafórico na compreensão textual, objetivo da pesquisa de tese que as autoras deste artigo estão desenvolvendo. Assim, ao relacionar processamento anafórico, capacidade de memória de trabalho e compreensão leitora, é possível compreender o papel que a anáfora, componente que atua na microestrutura do texto, exerce na compreensão textual e, ainda, como a memória de trabalho atua nesse processo, dentro da construção da própria microestrutura em conjunto com o tecido do texto.

Tendo feito o mapeamento, cabe, ainda, levantar a discussão a respeito das relações entre os resultados dos estudos sobre o processamento anafórico e a aprendizagem da leitura (relação não explorada nos estudos mapeados), o que contribuirá para a elaboração de planos instrucionais de ensino devidamente fundamentados em importantes achados científicos. Considerando-se que leitura se ensina, é fundamental que haja o 
conhecimento e a consideração dos fatores e elementos que atuam nessa complexa atividade de produção de sentidos. Entre tais fatores e elementos estão aspectos de natureza linguística e textual que, se não devidamente compreendidos, explorados e sistematicamente ensinados, podem levar à aleatoriedade e a baixo alcance, eficiência e eficácia do ensino.

Por fim, é relevante ressaltar que a relação entre os estudos experimentais, a teorização e o ensino traz importante contribuição à psicolinguística aplicada, uma vez que lança luz sobre construções e processos que estão muito próximos da base de aprendizagem da leitura, quando a alfabetização está vencida no nível da palavra e da frase e se avança para a teia que constrói o texto e que permite que o/a leitor/a o acesse e produza sentidos para além da compreensão básica. É com trabalho sério, planejado, fundamentado e sistematizado, baseado em estudos científicos (no caso específico deste tema de pesquisa, fundamentalmente desenvolvidos em universidades públicas), que se pode contribuir fortemente para a real democracia neste país, criando condições, em aspectos com quais se trabalha detidamente, para a redução da desigualdade social no que diz respeito ao acesso à cultura letrada.

\section{REFERÊNCIAS}

ALLIENDE, F.; CONDEMARÍN, M. A leitura: teoria, avaliação e desenvolvimento. Tradução Ernani Rosa. 8. ed. Porto Alegre: Artmed, 2005.

ALVERMANN, D. E.; UNRAU, N. J.; RUDDELL, R. B. Theoretical models and processes of reading. 6. ed. Newark, DE: International Reading Association, 2013.

ARAÚJO, E. M. de. Processamento correferencial das expressões "ele(a) mesmo(a)" e "ele(a) próprio(a)" em Português Brasileiro. 2017. Dissertação (Mestrado em Linguística) -Universidade Federal da Paraíba, João Pessoa, 2017.

BEZERRA, G. B. O processamento de argumentos e adjuntos em estruturas sintáticas sem ambiguidade e em estruturas com correferência. 2013. Dissertação (Mestrado em Linguística) -Universidade Federal da Paraíba, João Pessoa, 2013.

BEZERRA, G. B.; LEITÃO, M. M. O processamento de argumentos e adjuntos em construções sem ambiguidade estrutural. Veredas, v. 17, n. 2, p. 60-82, 2013.

BRASIL. Ministério da Saúde. Secretaria de Ciência, Tecnologia e Insumos Estratégicos. Departamento de Ciência e Tecnologia. Diretrizes metodológicas: elaboração de revisão sistemática e metanálise de ensaios clínicos randomizados. Brasília: Editora do Ministério da Saúde, 2012.

CAVALCANTE, L. C. F. Compreensão leitora de elementos anafóricos e de bumor em narrativas: um design experimental. 2017. Tese (Doutorado em Linguística) -Universidade Federal da Paraíba, João Pessoa, 2017.

CHOMSKY, N. Lectures on government and binding. Dodrecht, NL: Foris, 1981.

CHOMSKY, N. Knowledge of language, its nature, origin, and use. New York, NY: Praeger, 1986.

CORREIA, D. V. Relações entre memória procedimental e linguagem em pessoas que gaguejam: um estudo com base no processamento da correferência anafórica em português brasileiro. 2014. Dissertação (Mestrado em Linguística) - Universidade Federal da Paraíba, João Pessoa, 2014. 
CORREIA, D. V.; FERRARI-NETO, J.; LEITÃO, M. M. Processamento correferencial de nomes e pronomes do português brasileiro em pessoas portadoras de gagueira. Letras de Hoje, v. 48, n. 1, p. 59-67, 2013.

CUNHA-LIMA, M. L. Indefinido, anáfora e a construção textual da referência. 2004. Tese (Doutorado em Linguística) - Universidade Estadual de Campinas, Campinas, 2004.

DE-LA-TORRE-UGARTE-GUANILO, M. C.; TAKAHASHI, R. F.; BERTOLOZZI, M. R. Revisão sistemática: noções gerais. Revista da Escola de Enfermagem da USP, v. 45, n. 5, p. 1260-1266, 2011.

FLOOD, J. (ed.). Understanding reading comprehension. Newark, DE: International Reading Association, 1984.

GAGNÉ, E. D.; YEKOVICH, C. W.; YEKOVICH, F. R. The cognitive psychology of school learning. New York, NY: Harper Collins, 1993.

GIL, A. C. Como elaborar projetos de pesquisa. 6. ed. São Paulo: Atlas, 2017.

GONDIM, E. V. A. C. Investigação teórico-metodológica sobre a penalidade do nome repetido em Português Brasileiro. 2017. Dissertação (Mestrado em Linguística) - Universidade Federal da Paraíba, João Pessoa, 2017.

HALLIDAY, M. A. R.; HASAN, R. Cohesion in English. London: Longman, 1976.

HANKAMER, J.; SAG, I. A. Deep and surface anaphora. Linguistic Inquiry, v. 7, n. 3, p. 391-428, 1976.

HEINIG, O. L. de O. M. O papel do professor no processo da construção de sentido na leitura. In: SOUZA, A. C. de; SEIMETZ-RODRIGUES, C.; FINGER-KRATOCHVIL, C.; BARETTA, L.; BACK, A. C. Di P. (org.). Diálogos linguísticos para a leitura e a escrita. Florianópolis: Insular, 2019. p. 107-129.

HENRIQUE, J. G. A influência da reflexividade verbal no processamento anafórico. 2016. Dissertação (Mestrado em Linguística) - Universidade Federal da Paraíba, João Pessoa, 2016.

HIGGINS, J. P. T.; GREEN, S. Cochrane handbook for systematic reviews of interventions. West Sussex, UK: John Wiley \& Sons, 2008.

KAISER, E. Experimental paradigms in Psycholinguistics. In: PODESVA, R. J.; SHARMA, D. (ed.). Research methods in Linguistics. Cambridge: Cambridge University Press, 2013. p. 135-168.

KAMIL, M. L.; PEARSON, P. D.; MOJE, E. B.; AFFLERBACH, P. P. Handbook of reading research. v. IV. Nova York, NY: Routledge, 2011.

KENEDY, E. O problema do analfabetismo. In: MAIA, M. (org.). Psicolinguística e educação. Campinas: Mercado de Letras, 2018. p. 81-102.

KINTSCH, W. Comprehension: a paradigm for cognition. Cambridge: Cambridge University Press, 1998.

KINTSCH, W.; RAWSON, K. A. Compreensão. In: SNOWLING, M. J.; HULME, C. (org.). A ciência da leitura. Tradução Ronaldo Cataldo Costa. Porto Alegre: Penso, 2013. p. 227-244.

KOCH, I. G. V. Desvendando os segredos do texto. 5. ed. São Paulo: Cortez, 2006.

KOCH, I. V.; ELIAS, V. M. Ler e compreender: os sentidos do texto. 3. ed. São Paulo: Contexto, 2015. 
LEITÃO, M. M. Processamento co-referencial de nomes e pronomes em português brasileiro. Linguística, Rio de Janeiro, v. 1, n. 2, p. 235-258, 2005.

LEITÃO, M. M. Animacidade e paralelismo estrutural no processamento da correferência. Revista Linguística, v. 6, n. 1, p. 44-57, 2010.

LEITÃO, M. M.; SIMÕES, A. B. G. A influência da distância no processamento correferencial de pronomes e nomes repetidos no português brasileiro. Veredas, v. 15, p. 262-272, 2011.

LEZAMA, C. G. Processing repeated names, overt pronouns and null reference in Spanish. 2008. Dissertação (Mestrado em Linguística) - University of South Carolina, Columbia, 2008.

MAIA, M. Computação estrutural e de conjunto na leitura de períodos: um estudo de rastreamento ocular. In: MAIA, M. (org.). Psicolinguística e educação. Campinas: Mercado de Letras, 2018. p. 103-132.

MAIA, J. de C. O processamento de expressões correferenciais em português. 2013. Dissertação (Mestrado em Estudos Linguísticos) - Universidade Federal da Minas Gerais, Belo Horizonte, 2013.

MARCONI, M. de A.; LAKATOS, E. M. Metodologia do trabalho científico. 8. ed. São Paulo: Atlas, 2017.

MARCUSCHI, L. A. Produção textual, análise de gêneros e compreensão. São Paulo: Parábola, 2008.

McGUINNESS, D. O ensino da leitura: o que a ciência nos diz sobre como ensinar a ler. Tradução Luzia Araújo. Porto Alegre: Artmed, 2006.

MILHORANCE, L. P. S. Resolução da anáfora no contexto do sluicing: O caso do Português Brasileiro. 2014. Dissertação (Mestrado em Letras/Estudos da Linguagem) - Pontifícia Universidade Católica do Rio de Janeiro, Rio de Janeiro, 2014.

MORAIS, J. Alfabetizar para a democracia. Porto Alegre: Penso, 2014.

NEVES, I. C. B.; SOUZA, J. V.; SCHÄFFER, N. O.; GUEDES, P. C.; KLUSENER, R. Ler e escrever: compromisso de todas as áreas. 9. ed. Porto Alegre: UFRGS, 2011.

NOiBREGA-THERRIEN, S. M.; THERRIEN, J. Os trabalhos cientificos e o estado da questão: reflexoPes teoìrico-metodoloìgicas. 2004. Disponiìvel em: https://bit.ly/3rNSkmP. Acesso em: 31 dez. 2018.

OAKHILL, J.; CAIN, K.; ELBRO, C. Compreensão de leitura: teoria e prática. Tradução Adail Sobral. São Paulo: Hogrefe, 2017.

PERFETTI, C. A.; LANDI, N.; OAKHILL, J. A aquisição da habilidade de compreensão da leitura. In: SNOWLING, M. J.; HULME, C. (org.). A ciência da leitura. Tradução Ronaldo Cataldo Costa. Porto Alegre: Penso, 2013. p. 245-265.

PINTO, M. da G. C. Uma breve abordagem à leitura e à escrita na perspectiva da Psicolinguística. In: SOUZA, A. C. de; SEIMETZ-RODRIGUES, C.; FINGER-KRATOCHVIL, C.; BARETTA, L.; BACK, A. C. Di P. (org.). Diálogos linguísticos para a leitura e a escrita. Florianópolis: Insular, 2019. p. 85-106.

QUEIROZ, K. L. de. Processamento da correferência: pronomes lexicais, nomes repetidos, hiperônimos e hipônimos como formas de retomadas anafórica inter-sentencial do sujeito em Português Brasileiro. 2009. Dissertação (Mestrado em Linguística) - Universidade Federal da Paraíba, João Pessoa, 2009. 
RAMOS, A.; FARIA, P. M.; FARIA, A. Revisão sistemática de literatura: contributo para a inovação na investigação em Ciências da Educação. Revista Diálogo Educacional, v. 14, n. 41, p. 17-36, 2014.

RAMOS-VOSGERAU, D. S.; ROMANOWSKI, J. P. Estudos de revisão: implicações conceituais e metodológicas. Revista Diálogo Educacional, v. 14, n. 41, p. 165-189, 2014.

RUDDELL, R. B; RUDDELL, M. R.; SINGER, H. (ed.). Theoretical models and processes of reading. 4th ed. Newark, DE: International Reading Association, 1994.

RUDDELL, R. B.; UNRAU, N. J. Reading as a motivated meaning-construction process: The reader, the text, and the teacher. In: ALVERMANN, D. E.; UNRAU, N. J.; RUDDELL, R. B. (ed.). Theoretical models and processes of reading. 6. ed. Newark, DE: International Reading Association, 2013. p. 1015-1068.

SAMPAIO, R. F.; MANCINI, M. C. Estudos de revisão sistemática: um guia para síntese criteriosa da evidência científica. Revista Brasileira de Fisioterapia, São Carlos, v. 11, n. 1, p. 83-89, jan./ fev. 2007. Disponível em: https://bit.ly/2L4imRQ. Acesso em: 17 jan. 2020.

SAG, I.; HANKAMER, J. Toward a theory of anaphoric processing. Linguistics and Philosophy, v. 7, p. 325345, 1984.

SCHÜTZE, C.; SPROUSE, J. Judgment data. In: PODESVA, R. J.; SHARMA, D. (ed.). Research methods in Linguistics. Cambridge: Cambridge University Press, 2013. p. 27-50.

SCLIAR-CABRAL, L. Inter-relação entre o biológico e o cultural: psicolinguística e educação. In: MAIA, M. (org.). Psicolinguística e educação. Campinas: Mercado de Letras, 2018. p. 25-55.

SEIMETZ-RODRIGUES, C.; SOUZA, A. C. de. Ensino da leitura a surdos: o conhecimento do objeto de ensino e suas implicações para a prática pedagógica. Linguagem \& Ensino, v. 19, n. 1, p. 55-79, 2016.

SEVERINO, A. J. Metodologia do trabalho científico. 24. ed. São Paulo: Cortez, 2017.

SIMÕES, A. B. G. A influência da coesão e da coerência no processamento correferencial de pronomes e nomes repetidos em português brasileiro. 2014. Dissertação (Mestrado em Linguística) - Universidade Federal da Paraíba, João Pessoa, 2014.

SNOWLING, M. J.; HULME, C. (org.). A ciência da leitura. Tradução Ronaldo Cataldo Costa. Porto Alegre: Penso, 2013.

SOARES, M. Alfabetização: a questão dos métodos. São Paulo: Contexto, 2016.

SOLÉ, I. Estratégias de leitura. Tradução Cláudia Schilling. 6. ed. Porto Alegre: Artmed, 1998.

SOUZA, A. C. de. Leitura, metáfora e memória de trabalbo: três eixos imbricados. 2004. Tese (Doutorado em Linguística) - Universidade Federal de Santa Catarina, Florianópolis, 2004.

SOUZA, A. C. de; BACK, A. C. Di P.; FINGER-KRATOCHVIL, C. Projeto Ler \& Educar. formação continuada de professores da rede pública de SC. 2012. Programa Observatório da Educação, Edital no. 049/212/CAPES.

SOUZA, A. C. de; FRANZEN, B. A.; SCHILICHTING, T. de S. Método na pesquisa psicolinguística sobre leitura: técnicas de coleta de dados. Fórum Linguístico, v. 16, n. 2, p. 3849-3860, abr./jun. 2019. 
SOUZA, A. C. de; GARCIA, W. A. da C. A produção de sentidos e o leitor. os caminhos da memória. Florianópolis: NUP-CED, 2012.

SOUZA, A. C. de; JUNKES, L. Aspectos da formação (psico)linguística do/a professor/a alfabetizador/a: o conhecimento do sistema fonológico e o ensinar a ensinar a ler. In: BACK, A. C. Di P.; CECHINEL, A.; JESUS, T. D. de (org.). Educação, linguagem e memória: outras histórias. Criciúma: Ediunesc. No prelo.

SOUZA, A. C. de; SEIMETZ-RODRIGUES, C.; WEIRICH, H. C. Ensinar a estudar ensinando a ler: potências dos roteiros de leitura. In: SOUZA, A. C. de; SEIMETZ-RODRIGUES, C.; FINGERKRATOCHVIL, C.; BARETTA, L.; BACK, A. C. Di P. (org.). Diálogos linguísticos para a leitura e a escrita. Florianópolis: Insular, 2019. p. 164-200.

TEIXEIRA, E. N. Preferências sintáticas e semânticas no processamento da correferência anafórica: evidências de movimentação ocular. 2013. Tese (Doutorado em Linguística) -Universidade Federal do Ceará, Fortaleza, 2013.

TEIXEIRA, E. N.; FONSECA, M. C. M.; SOARES, M. E. Resolução do pronome nulo em Português Brasileiro: evidência de movimentação ocular. Veredas, v. 18, n. 1, p. 281-301, 2014. 